\title{
CONTROLE DE PRAGAS E DOENÇAS, MATURAÇÃO E QUALIDADE DE MAÇÃS 'IMPERIAL GALA' SUBMETIDAS AO ENSACAMENTO'
}

\author{
ROSÂNGELA TEIXEIRA², CASSANDRO VIDAL TALAMINI DO AMARANTE ${ }^{3}$, \\ MARI INÊS CARISSIMI BOFF ${ }^{4}$, LUIZ GONZAGA RIBEIRO 5
}

RESUMO - O objetivo deste trabalho foi avaliar a eficiência de diferentes embalagens no ensacamento de maçãs para o controle de pragas e doenças, e sua influência na maturação e qualidade dos frutos, em pomar sob sistema orgânico. O experimento foi conduzido em pomar com plantas de dez anos de idade da cultivar Imperial Gala, sobre porta-enxerto 'Marubakaido', com filtro EM-9, localizado no município de São JoaquimSC, nas safras 2007/2008 e 2008/2009. Os frutos foram ensacados, após o raleio, com embalagens plásticas transparentes microperfuradas ou de tecido não texturizado (TNT). Frutos não ensacados constituíram o tratamento-controle. Na colheita, os frutos foram avaliados quanto aos danos provocados por mosca-dasfrutas (Anastrepha fraterculus), mariposa-oriental (Grapholita molesta), lagarta-enroladeira (Bonagota salubricola) e pulgão-lanígero (Eriosoma lanigerum), incidência das doenças sarna-da-macieira (Venturia inaequalis) e podridão-amarga (Colletotrichum gloeosporioides), e atributos físico-químicos de maturação e qualidade e teor de cálcio $(\mathrm{Ca})$ nos frutos. $\mathrm{O}$ ensacamento, independentemente do tipo de material utilizado, reduziu os danos de insetos-praga, porém não foi eficiente no controle de doenças nos frutos. O ensacamento não comprometeu o desenvolvimento de coloração vermelha na casca e o teor de Ca nos frutos. De modo geral, o ensacamento antecipou o processo de maturação, caracterizado pela redução na firmeza de polpa e na textura da casca e da polpa, e pelo aumento no índice de iodoamido.

Termos para indexação: Malus domestica, manejo fitossanitário, produção orgânica.

\section{CONTROL OF INSECT PESTS AND DISEASES, MATURITY AND QUALITY OF 'IMPERIAL GALA' APPLES SUBMITTED TO BAGGING}

\begin{abstract}
This work was carried out to evaluate the efficiency of different fruit bagging materials to insect pests and diseases control, and its influence on maturity and quality of the fruits in an organic apple orchard. The experiment was conducted in a ten years old orchard of 'Imperial Gala' apple trees grafted on 'Marubakaido' rootstock (with a filter of EM-9), in São Joaquim, State of Santa Catarina, in 2007/08 and 2008/09. The apples were bagged after fruit thinning, with bags made of transparent micro-perforated plastic or non-textured fabric. The control treatment consisted of unbagged fruit. At harvest, fruits were assessed for damages caused by fruit fly (Anastrepha fraterculus), oriental fruit moth (Grapholita molesta), apple leafroller (Bonagota salubricola) and woolly apple aphid (Eriosoma lanigerum), incidence of the apple scab (Venturia inaequalis) and bitter rot (Colletotrichum gloeosporioides) diseases, as well as for physicochemical attributes of maturity and quality, and calcium $(\mathrm{Ca})$ content of the fruit. Fruit bagging, regardless of the material used, reduced the damages caused by insect pests, but did not protect fruit against diseases caused by the evaluated fungus. Fruit bagging did not affect the development of the red color and Ca content of the fruit. In general, the bagging anticipated the fruit maturation process, characterized by the reduction on flesh firmness and skin and pulp texture, and by the increase of the starch-iodine index.
\end{abstract}

Index terms: Malus domestica, phytossanitary management, organic production.

\footnotetext{
${ }^{1}$ (Trabalho 106-10). Recebido em: 26-04-2010. Aceito para publicação em: 05-11-2010.

${ }^{2}$ Acadêmica do Curso de Mestrado em Produção Vegetal da Universidade do Estado de Santa Catarina (UDESC). Centro de Ciências Agroveterinárias (CAV), Av. Luiz de Camões, 2090, Bairro Conta Dinheiro, CEP 88520-000, Lages-SC, Brasil. E-mail: rmt-biologa@hotmail.com ${ }^{3}$ Ph.D., bolsista de produtividade em pesquisa do CNPq, Professor do Departamento de Agronomia, CAV/UDESC. Av. Luiz de Camões, 2090, Bairro Conta Dinheiro, CEP 88520-000, Lages-SC. E-mail: amarante@cav.udesc.br

${ }^{4}$ Ph.D., Professora do Departamento de Agronomia, CAV/UDESC. Av. Luiz de Camões, 2090, Bairro Conta Dinheiro, CEP 88520000, Lages-SC, Brasil. Autor para correspondência. E-mail: 2micb@cav.udesc.br

${ }^{5}$ Pesquisador da Empresa de Pesquisa Agropecuária e Extensão Rural de Santa Catarina (EPAGRI), Estação Experimental de São Joaquim. Rua José Araújo Lima, 102, Bairro Jardim Caiçara, CEP 88.600-000, São Joaquim-SC, Brasil. E-mail: lega@epagri.sc.gov.br
} 


\section{INTRODUÇÃO}

A macieira é uma fruteira de clima temperado que apresenta papel importante na economia brasileira, principalmente na região Sul (ASSOCIAÇÃO BRASILEIRA DE PRODUTORES DE MAÇÃ, 2003). Todavia, o cultivo da macieira enfrenta problemas fitossanitários relacionados ao ataque de pragas e doenças que, dependendo do nível de danos aos frutos, pode provocar depreciação na qualidade e redução no seu valor comercial (SANTOS; WAMSER, 2006). No cultivo convencional, são utilizados diversos inseticidas e fungicidas, alguns com restrição de uso para maçãs destinadas à exportação. Devido à preocupação com os riscos à saúde humana e com os efeitos ambientais indesejáveis, mais agricultores estão interessados na produção orgânica de maçãs (AMARANTE et al., 2008).

$\mathrm{Na}$ agricultura orgânica, são poucas as alternativas para manejo e controle fitossanitário, principalmente de pragas. O ensacamento é uma técnica utilizada neste sistema de produção, que apresenta resultados promissores (PINHEIRO, 2006). Em tomate, pera e graviola, o ensacamento de frutos tem apresentado resultados positivos na proteção contra o ataque de pragas (JORDÃO; NAKANO, 2002; MICHELETTI et al., 2001; FAORO, 2003). O ensacamento dos cachos de uva de mesa tem reduzido o ataque de insetos, além de proporcionar uniformidade de coloração das bagas. Em peras, o ensacamento dos frutos com filme de polietileno microperfurado reduziu os dano de pássaros e por fricção na casca, e o resíduo de pesticidas nos frutos (AMARANTE et al., 2002a).

Apesar de a técnica do ensacamento de frutos ser bastante utilizada, não existe ainda um material mais adequado para a confecção das embalagens. Muitos agricultores utilizam sacos de papel que, no entanto, mostram-se frágeis à ocorrência de chuvas, não apresentando durabilidade e segurança na proteção dos frutos durante todo o ciclo da cultura, sendo necessário, na maioria das vezes, trocá-los. Além disso, os sacos de papel podem oferecer proteção para alguns tipos de pragas e aumentar a incidência de outras, devido ao microclima formado no entorno do fruto (MARTINS et al., 2007). Em goiabeiras, a proteção dos frutos com sacos de papel foi eficiente no controle de mosca-das-frutas, porém aumentou a incidência de injúrias mecânicas e doenças póscolheita (MARTINS et al., 2007). A utilização de sacos de papel impede a avaliação visual da coloração da epiderme dos frutos, utilizada pelos agricultores na identificação do momento certo da colheita (COELHO et al., 2008a). Além disso, o sombreamento resultante do ensacamento pode reduzir a coloração vermelha da epiderme (HOFMAN et al., 1997; JIA et al., 2004; SANTOS et al., 2007), e a barreira mecânica imposta pelo saco reduz o suprimento de cálcio $(\mathrm{Ca})$ aos frutos, aplicado via pulverizações na pré-colheita.

Este trabalho teve o objetivo de avaliar a eficiência do ensacamento de maçãs 'Imperial Gala' com embalagens plásticas transparentes microperfuradas e de tecido não texturizado, no controle de pragas e doenças, e seus efeitos na maturação e qualidade dos frutos, em pomar conduzido sob sistema orgânico.

\section{MATERIAL E MÉTODOS}

O experimento foi realizado nas safras 2007/2008 e 2008/2009, em um pomar de maçãs localizado no município de São Joaquim-SC (situada a $28^{\circ} 15^{\prime}$ de latitude $\mathrm{S}$ e $49^{\circ} 54^{\prime}$ de longitude W, com altitude de $1.360 \mathrm{~m}$, clima mesotérmico úmido, temperatura média de $14,1{ }^{\circ} \mathrm{C}$ e precipitação anual de $1.695 \mathrm{~mm}$ ), conduzido sob o sistema orgânico. O pomar, composto por filas intercaladas de macieiras 'Imperial Gala' e 'Fuji Suprema', com dez anos de idade, sobre porta-enxerto 'Marubakaido', com filtro EM-9, apresentava espaçamento entre plantas de $2 \mathrm{~m} \times 5 \mathrm{~m}$.

Os tratamentos constaram de frutos ensacados em saco plástico transparente micro-perfurado, frutos ensacados em saco de tecido não texturizado (TNT) e frutos não ensacados (testemunha). O ensacamento foi realizado no período de raleio dos frutos, aproximadamente 40 dias após a plena floração. Os frutos permaneceram ensacados até a colheita. $\mathrm{O}$ experimento seguiu o delineamento em blocos ao acaso, com dez repetições, cada repetição correspondendo a uma planta.

Os frutos foram colhidos no ponto de maturação comercial. No momento da colheita, ainda no campo, todos os frutos de cada planta (repetição) foram avaliados, observando-se os danos provocados pela mosca-das-frutas Anastrepha fraterculus Wiedemann, 1830 (Diptera: Tephritidae), mariposaoriental Grapholita molesta (Busck) (Lepidoptera: Tortricidae), lagarta-enroladeira, Bonagota salubricola (Meyrick) (Lepidoptera: Tortricidae), pulgãolanígero Eriosoma lanigerum (Hausmann) (Homoptera: Aphididae) e outras pragas (danos de grandes lagartas, pássaros e outros não identificados). Os frutos foram também avaliados quanto à incidência das doenças sarna-da-macieira Venturia inaequalis (Cke.) Wint. e podridão-amarga Colletotrichum gloeosporioides (Penzig) Saccardo .

Amostras aleatórias de 20 frutos de cada 
repetição (com pesos médios de $122 \mathrm{~g}$ e $177 \mathrm{~g}$ nas safras 2007/2008 e 2008/2009, respectivamente) foram transportadas para o Laboratório de Fisiologia e Tecnologia Pós-Colheita, no Centro de Ciências Agroveterinárias (CAV), em Lages-SC, para a realização das análises de atributos físico-químicos e de qualidade dos frutos. Foram feitas avaliações nos frutos de teor de sólidos solúveis (SS), acidez titulável (AT), firmeza de polpa, índice de iodoamido, textura de casca e polpa, coloração, densidade, severidade de "russet", incidência de queimadura de sol e teor de cálcio $(\mathrm{Ca})$.

Em amostras compostas de suco, extraídas de 20 frutos de cada repetição, foram feitas as determinações de teor de SS ( ${ }^{\circ}$ Brix; com um refratômetro manual, com compensação automática de temperatura) e AT (\% de ácido málico; através de titulometria de neutralização com $\mathrm{NaOH} 0,1 \mathrm{~N}$, até pH 8,1).

A firmeza da polpa (Newton; N) foi quantificada na região equatorial dos frutos, em dois lados opostos, após remoção de uma pequena camada da epiderme, com auxílio de um penetrômetro modelo Effegi, equipado com ponteira de $11,1 \mathrm{~mm}$ de diâmetro.

O índice de iodoamido foi avaliado numa escala de 1 (toda a superfície corada com iodo, correspondendo à predominância de amido e fruto imaturo) a 5 (toda a superfície não corada com iodo, correspondendo à predominância de açúcares solúveis e fruto totalmente maduro).

A textura de casca e polpa foi avaliada com um texturômetro eletrônico TAXT-Plus ${ }^{\circledR}$ (Stable Micro Systems Ltda., Reino Unido). Para a quantificação da força (Newton; $\mathrm{N}$ ) necessária para o rompimento da epiderme e para a penetração na polpa, foi utilizada ponteira modelo PS2, com $2 \mathrm{~mm}$ de diâmetro, a qual foi introduzida na polpa a uma profundidade de $8 \mathrm{~mm}$, com velocidades de pré-teste, teste e pós-teste de 10; 1 e $10 \mathrm{~mm} \mathrm{~s}^{-1}$, respectivamente.

A coloração foi avaliada em termos de superfície colorida do fruto (percentagem de cor vermelha), por meio de análise subjetiva visual, e de valores de brilho $(L)$, croma $(C)$ e ângulo 'hue' $\left(h^{o}\right)$, com o auxílio de um colorímetro Minolta, modelo CR 400, nos lados mais e menos expostos à luz (correspondentes aos lados com maior e menor intensidade de coloração vermelha, respectivamente).

Os frutos foram ainda avaliados quanto à densidade $\left(\mathrm{g} \mathrm{cm}^{-3}\right)$, através de método envolvendo a pesagem dos frutos, com ou sem imersão total em água, e severidade de "russet" $\left(\mathrm{cm}^{2}\right.$ fruto $\left.^{-1}\right)$, através de análise visual subjetiva. Também foi avaliada a incidência (\%) de frutos com queimaduras de sol.

Para avaliação de teor de $\mathrm{Ca}\left(\mathrm{mg} \mathrm{kg}^{-1}\right.$ de massa fresca), foram retiradas duas fatias longitudinais (menos pedúnculo e semente) em cada fruto, contendo tecidos de casca e polpa. Destas amostras, foram utilizados aproximadamente $5 \mathrm{~g}$ de tecido (polpa e casca), pesados e transferidos para a mufla em cadinhos, com temperatura ajustada gradativamente até $630^{\circ} \mathrm{C}$, sendo mantidos nessa temperatura durante quatro horas. Em seguida, as amostras foram retiradas, adicionando-se $15 \mathrm{~mL}$ de solução de $\mathrm{HCl}$ (1,8 $\left.\mathrm{mol} \mathrm{L}^{-1}\right)$, seguindo de homogeneização. Para a quantificação do $\mathrm{Ca}$, foram utilizados $3,0 \mathrm{~mL}$ do extrato elaborado (coletado com seringa calibrada), adicionando-se 3,0 mL de solução de lantânio. A amostra foi homogeneizada, sendo efetuada a leitura de teor de $\mathrm{Ca}\left(\mathrm{mg} \mathrm{kg}^{-1}\right.$ de massa fresca) em um espectrofotômetro de absorção atômica.

Os dados foram submetidos à análise de variância e a teste de comparação de médias (teste de Tukey; $p<0,05$ ), com o programa SAS (SAS Institute, 2002).

\section{RESULTADOS E DISCUSSÃO}

As embalagens de plástico transparente microperfurado e TNT resistiram às variações das condições climáticas ocorridas no decorrer da safra, garantindo assim proteção aos frutos até a colheita. Os sacos de TNT mostraram condições de ser reutilizados numa próxima safra.

\section{Ocorrência de pragas e doenças}

$\mathrm{O}$ ensacamento dos frutos reduziu o ataque de pragas, independentemente do tipo de embalagem utilizada (Tabela 1). Nas duas safras, os frutos ensacados com ambos os tipos de embalagens não apresentaram sintoma de deformação, que ocorre devido ao ataque da mosca-das-frutas logo no início do desenvolvimento dos frutos. Independentemente do tipo de embalagem, maçãs ensacadas apresentaram também redução significativa de galerias causadas pelas larvas da mosca-das-frutas (Tabela 1). Santos e Wamser (2006) também reportam em maçãs 'Royal Gala' e 'Fuji Suprema', submetidas ao ensacamento, menor infestação de mosca-das-frutas ( $4 \%$ de danos), comparativamente a frutos não ensacados $(20 \%$ de danos). Em goiabeiras cultivadas em sistema orgânico, o ensacamento dos frutos também reduziu o ataque de mosca-das-frutas (PINHEIRO, 2006).

$\mathrm{O}$ ensacamento protegeu os frutos do ataque de mariposa-oriental ( $G$. molesta) em ambas as safras (Tabela 1). Resultados semelhantes foram observados por Santos e Wamser (2006), utilizando saco de papel-manteiga e saco plástico microperfurado em maçãs. 
Na safra 2007/2008 a ocorrência da lagartaenroladeira (B. salubricola) foi baixa e não houve diferença significativa entre os tratamentos. Porém, na safra 2008/2009, o índice de infestação foi significativamente menor nos frutos ensacados (Tabela 1). O ensacamento conferiu proteção significativa aos frutos de maçã contra danos causados por grandes lagartas, pássaros e outros organismos não identificados (Tabela 1).

Embora o pulgão-lanígero (E. lanigerum) seja uma espécie frequente na cultura da macieira, sua ocorrência não foi verificada em ambas as safras.

$\mathrm{O}$ ensacamento foi menos eficiente no controle de doenças, comparativamente aos resultados obtidos no controle de pragas (Tabela 1).

Nas duas safras, o ensacamento não foi eficiente no controle de sarna-da-macieira (Tabela 1). Na região de São Joaquim-SC, a liberação de ascósporos (na fase parasítica ou assexuada do fungo causador da sarna-da-macieira (Venturia inaequalis)) inicia-se em agosto, pouco antes da brotação da macieira, atinge o pico durante a floração, nos meses de setembro e outubro, e encerra-se em novembro (BONETI et al., 2002). Portanto, como a infecção pelo patógeno ocorre na floração e início do desenvolvimento dos frutos, o ensacamento, realizado após o raleio de frutos, apresenta baixa eficiência no controle de sarna nos frutos.

Houve baixa ocorrência de podridão-amarga nas duas safras (Tabela 1). Na safra 2007/2008, houve maior incidência de podridão-amarga em frutos ensacados com embalagem plástica. Isto pode estar relacionado à alta ocorrência de chuvas nesta safra e à manutenção de alta umidade no interior da embalagem plástica. Segundo Boneti et al. (2002), em regiões mais quentes e com alto índice pluviométrico, os danos causados pela podridão-amarga na cultura da macieira são mais severos. Na safra 2008/2009, o ensacamento com os dois tipos de embalagens reduziu a incidência de podridão-amarga em relação à testemunha (Tabela 1 ).

Resultados diferentes, no controle de doenças, foram reportados em lichia, mostrando que o ensacamento com embalagem de polietileno reduziu infecções causadas por fungos, que causam o escurecimento e o apodrecimento dos frutos (KOOARIYALKUL; SARDSUD, 1998). Em manga, o ensacamento com embalagem de papel diminuiu a incidência e a severidade de antracnose, comprovando sua eficácia como barreira mecânica, oferecendo proteção aos frutos (HOFFMAN et al., 1997).

\section{Maturação e qualidade dos frutos}

Os teores de SS e a AT em frutos ensacados com os dois tipos de embalagens não diferiram do tratamento-controle, em ambas as safras (Tabela 2). Resultados similares foram reportados em pêssegos (JIA et al., 2004), mangas (HOFMAN et al., 1997) e peras (AMARANTE et al., 2002b) submetidos ao ensacamento.

Na safra 2007/2008, a firmeza de polpa não diferiu entre tratamentos, mas na safra 2008/2009 foi menor em frutos ensacados, especialmente com a utilização da embalagem de plástico microperfurado (Tabela 2). O índice de iodoamido foi maior em frutos ensacados com os dois materiais, em ambas as safras (Tabela 2), indicando maior degradação de amido e estádio de maturação mais avançado em relação à testemunha. A textura de polpa e a textura de casca, nas safras 2007/2008 e 2008/2009, respectivemente, não diferiram entre os tratamentos (Tabela 2). Todavia, a textura de polpa foi menor em frutos ensacados, independentemente do material, na safra $2008 / 2009$, enquanto a textura da casca foi menor nos frutos ensacados com material plástico na safra 2007/2008 (Tabela 2).

Estes resultados mostram que o ensacamento pode acelerar o processo de maturação de maçãs 'Imperial Gala', caracterizado principalmente pela redução na firmeza de polpa e na textura da casca e da polpa, e pelo aumento no índice de iodoamido, sendo este efeito dependente do tipo de material utilizado e da safra (Tabela 2). Foi observado aumento da temperatura no interior das embalagens de plástico microperfurado e de TNT, durante o dia, de 2-3 ${ }^{\circ} \mathrm{C}$, o que pode acelerar o processo de maturação dos frutos. Uvas de mesa ensacadas apresentaram antecipação da maturação (OSTAPIV et al., 2006), sendo os resultados dependentes do tipo de material utilizado na confecção das embalagens e da safra (SIGNES et al., 2007).

O ensacamento não afetou a cor da epiderme (atributos $L, C$ e $h^{\circ}$ ) (Tabela 3 ) e a percentagem de cor vermelha (Tabela 4) dos frutos na safra 2007/2008. Na safra 2008/2009, o ensacamento com os dois materiais não reduziu a percentagem de cor vermelha dos frutos (Tabela 4), mas reduziu a intensidade de cor vermelha no lado do fruto menos exposto à luz, caracterizada pelos maiores valores dos atributos de cor $L$ (brilho) e $h^{o}$ (ângulo 'hue') da epiderme em relação à testemunha (Tabela 3 ).

A coloração do fruto é o atributo de qualidade mais atrativo para o consumidor (CHITARRA; CHITARRA, 2005), e pode ser afetado pelo ensacamento (HOFMAN et al., 1997; AMARANTE et al., 2002b; JIA et al., 2004; SANTOS et al., 2007). A macieira é uma espécie que exige alta densidade de fluxo radiante, principalmente na fase de maturação, pois a 
luz solar promove a síntese de antocianinas, tornando os frutos mais vermelhos (SANTOS et al., 2007; COELHO et al., 2008a). Neste trabalho, o ensacamento dos frutos com os dois tipos de embalagens não afetou a percentagem de cor vermelha em maçãs 'Imperial Gala' Tabela 4), já que esta cultivar apresenta maior acúmulo de antocianinas na casca em relação à 'Gala' comum (CAMILO; DENARDI, 2002). Os resultados obtidos foram diferentes daqueles reportados para maçãs 'Royal Gala' (SANTOS et al., 2007) e peras 'Doyenne du Comice' (AMARANTE et al., 2002b), nos quais o emprego de sacos plásticos microperfurados resultou em redução na cor vermelha (maiores valores de $h^{\circ}$ e $L$ ) dos frutos. Em pêssego e manga, houve redução no $h^{\circ}$ e aumento no $C$ da epiderme em frutos ensacados com embalagem de papel, em relação a frutos não ensacados (JIA et al., 2004; HOFMAN et al., 1997). Foi reportada redução na porcentagem de cor vermelha e na cor de fundo da epiderme, em pêssego ensacado com embalagens de TNT (de diferentes colorações) e de polipropileno microperfurado transparente (COELHO et al., 2008b), em caqui ensacado com embalagem de papel manteiga e jornal (BIASI et al., 2007), e em maçãs 'Royal Gala’ e Fuji Suprema’ ensacadas com embalagem de papel-manteiga e polipropileno microperfurado transparente (SANTOS et al., 2007).

Em ambas as safras, não houve diferença significativa na densidade dos frutos, submetidos ou não ao ensacamento (Tabela 4). Amarante et al. (2002b) também não verificaram diferenças na densidade de peras submetidas ao ensacamento com embalagem plástica microperfurada.

A ocorrência de "russet" foi baixa na safra 2007/2008, não havendo diferença significativa entre os tratamentos (Tabela 4). Entretanto, na safra $2008 / 2009$, foi observada maior severidade deste distúrbio nos frutos ensacados com TNT (Tabela 4). Santos et al. (2007) não observaram influência do ensacamento dos frutos com papel-manteiga na incidência de "russet" em diferentes cultivares de maçãs. A ocorrência maior de "russet", em frutos ensacados com embalagem de TNT, pode ser resultado da maior umidade que se forma junto à epiderme do fruto. As chuvas ocasionam o umedecimento do TNT, o que causa o molhamento do fruto e eleva a umidade no interior da embalagem, podendo assim aumentar a ocorrência de "russet". A embalagem plástica microperfurada, por sua vez, seca rapidamente e não permite um aumento na umidade no seu interior, devido às micro-perfurações, reduzindo assim a incidência de "russet".

A ocorrência de queimadura de sol foi influenciada pelo tipo de material utilizado no ensacamento.
Nas duas safras, os frutos ensacados com embalagem plástica microperfurada apresentaram maior incidência de queimadura de sol do que frutos ensacados com embalagem de TNT e a testemunha (Tabela 4). Resultados semelhantes foram observados por Santos et al. (2007), em que maçãs ensacadas com embalagem plástica microperfurada apresentaram maior incidência de queimadura de sol. Como o saco plástico é transparente, não protege do excesso de radiação, que causa a queimadura de sol. Aliado a isso, a embalagem pode aderir à epiderme do fruto, e o aquecimento do plástico pela radiação solar pode agravar o dano causado pela queimadura do sol (SANTOS; WANSER, 2006). No entanto, materiais que protegem o fruto da radiação excessiva, como as embalagens de TNT (Tabela 4) ou de papel-manteiga (SANTOS et al., 2007), reduzem a queimadura de sol em maçãs.

O teor de Ca nos frutos não foi influenciado pelo ensacamento, nas duas safras avaliadas (com valores médios, das duas safras, para os tratamentostestemunha, saco plástico e saco TNT de 44,24 $\pm 3,01$, $54,28 \pm 6,60$ e 48,71 $\pm 3,00 \mathrm{mg} \mathrm{kg}^{-1}$ de massa fresca, respectivamente). Os teores de $\mathrm{Ca}$ obtidos foram superiores a $35 \mathrm{mg} \mathrm{kg}^{-1}$ de massa fresca, nível considerado adequado para evitar a acorrência de "bitter pit" durante o armazenamento refrigerado dos frutos (AMARANTE et al., 2008). O ensacamento de peras com embalagem plástica microperfurada não afetou os teores de $\mathrm{Ca}, \mathrm{Mg}, \mathrm{K}, \mathrm{P}$ e N nos frutos (AMARANTE et al., 2002b). Joice et al. (1997) afirmam que o ensacamento de mangas com embalagens de plástico e papel não interfere no teor de $\mathrm{Ca}$ dos frutos.

Os resultados obtidos mostram que o ensacamento, independentemente do tipo de material utilizado, representa uma técnica eficiente no controle de danos de insetos-praga aos frutos de maçãs. No entanto, esta técnica não se mostra eficiente no controle das principais doenças que ocorrem nos frutos, pois os patógenos podem ocasionar infecção antes do ensacamento. De modo geral, o ensacamento antecipou o processo de maturação e não comprometeu o desenvolvimento de coloração vermelha na casca e o teor de Ca em maçãs 'Imperial Gala'. 
TABELA 1 - Danos de pragas e incidência de doenças em frutos de macieiras 'Imperial Gala' submetidos ao ensacamento pré-colheita, em pomar conduzido sob sistema orgânico. São Joaquim-SC, safras 2007/2008 e 2008/2009.

\begin{tabular}{|c|c|c|c|c|c|c|c|}
\hline \multirow{3}{*}{ Tratamento } & \multicolumn{5}{|c|}{ Pragas $(\%)$} & \multicolumn{2}{|c|}{ Doenças $(\%)$} \\
\hline & \multicolumn{2}{|c|}{ Mosca-das-frutas } & \multirow{2}{*}{$\begin{array}{l}\text { Mariposa- } \\
\text { oriental }\end{array}$} & \multirow{2}{*}{$\begin{array}{c}\text { Lagarta- } \\
\text { enroladeira }\end{array}$} & \multirow{2}{*}{ Outras pragas } & \multirow{2}{*}{$\begin{array}{l}\text { Sarna-da- } \\
\text { macieira }\end{array}$} & \multirow{2}{*}{$\begin{array}{c}\text { Podridão- } \\
\text { amarga }\end{array}$} \\
\hline & Deformação & Galeria & & & & & \\
\hline & \multicolumn{7}{|c|}{ Safra 2007/08 } \\
\hline Testemunha & $50+2859$ & $98,00 \pm 2,00 \mathrm{a}$ & $3,16 \pm 0,74 \mathrm{a}$ & $1,65 \pm 0,51 \mathrm{a}$ & & & $0,69 \pm 0,00 \mathrm{~b}$ \\
\hline & $0,06 \pm 0,0$ & & $0,89 \pm 0,40 \mathrm{~b}$ & $0,78 \pm$ & & & \\
\hline \multirow[t]{2}{*}{ Saco de TNT } & $0,00 \pm 0,00 \mathrm{~b}$ & $0,00 \pm 0,00 \mathrm{~b}$ & $1,26 \pm 0,48 b$ & $0,65 \pm 0,29 \mathrm{a}$ & & $62,87 \pm 5,2 \mathrm{a}$ & $0,88 \pm 0,40 \mathrm{~b}$ \\
\hline & \multicolumn{7}{|c|}{ Safra 2008/09 } \\
\hline & $98,89 \pm 0,46 \mathrm{a}$ & $100,0=$ & $1,62 \pm 0,43 a$ & $2,53 \pm 0,33 \mathrm{a}$ & & $0,69 \pm 0,0 \mathrm{~b}$ & $1,18 \pm 0,69 b$ \\
\hline & $3,65 \pm 0,7$ & $0,00 \pm$ & $0,00 \pm 0,00 \mathrm{~b}$ & $1,41=$ & & $1,97 \pm 0,7 \mathrm{a}$ & $0,00 \pm 0,00 \mathrm{a}$ \\
\hline Saco de TNT & $4,92 \pm 1,00 \mathrm{~b}$ & $4,00 \pm 2,66 b$ & $0,95 \pm 0,09 \mathrm{~b}$ & $1,24 \pm 0,61 b$ & $7,66 \pm 2,34 b$ & $0,88 \pm 0,4 b$ & $0,09 \pm 0,40 \mathrm{a}$ \\
\hline
\end{tabular}

Médias seguidas pela mesma letra, nas colunas, não diferem pelo teste de Tukey $(\mathrm{p}<0,05)$.

TABELA 2 - Atributos de maturação em frutos de macieiras 'Imperial Gala' submetidos ao ensacamento pré-colheita, em pomar conduzido sob sistema orgânico. São Joaquim-SC, safras 2007/2008 e 2008/2009.

\begin{tabular}{|c|c|c|c|c|c|c|}
\hline Tratamentos & $\begin{array}{c}\text { Sólidos solúveis } \\
\left({ }^{\circ} \text { Brix }\right)\end{array}$ & $\begin{array}{c}\text { Acidez titulável } \\
(\%)\end{array}$ & $\begin{array}{l}\text { neza da polpa } \\
(\mathrm{N})\end{array}$ & $\begin{array}{l}\text { Índice de } \\
\text { iodoamido (1-5) }\end{array}$ & $\begin{array}{c}\text { Textura da casca } \\
\text { (N) }\end{array}$ & $\begin{array}{l}\text { Textura da polpa } \\
\text { (N) }\end{array}$ \\
\hline & \multicolumn{6}{|c|}{ Safra $2007 / 08$} \\
\hline Testemunha & $12,41 \pm 0,08 \mathrm{a}$ & $0,47 \pm 0,03 \mathrm{ab}$ & $89,0 \pm 0,05 \mathrm{a}$ & $3,8 \pm 0,04 \mathrm{~b}$ & $12,10 \pm 0,03 \mathrm{a}$ & $3,36 \pm 0,12 \mathrm{a}$ \\
\hline Saco plástico & $12,62 \pm 0,01 \mathrm{a}$ & $0,46 \pm 0,00 \mathrm{~b}$ & $88,1 \pm 0,07 \mathrm{a}$ & $4,4 \pm 0,11 \mathrm{a}$ & $11,49 \pm 0,04 \mathrm{~b}$ & $3,07 \pm 0,10 \mathrm{a}$ \\
\hline \multirow[t]{2}{*}{ Saco de TNT } & $12,72 \pm 0,09 \mathrm{a}$ & $0,50 \pm 0,06 \mathrm{a}$ & $90,4 \pm 0,08 \mathrm{a}$ & $4,2 \pm 0,09 \mathrm{a}$ & $12,13 \pm 0,08 \mathrm{a}$ & $3,55 \pm 0,07 \mathrm{a}$ \\
\hline & \multicolumn{6}{|c|}{ Safra $2008 / 09$} \\
\hline Testemunha & $13,96 \pm 0,03 \mathrm{a}$ & $0,44 \pm 0,00 \mathrm{a}$ & $85,8 \pm 0,04$ a & $4,2 \pm 0,11 \mathrm{~b}$ & $11,05 \pm 0,03 \mathrm{a}$ & $4,30 \pm 0,02 \mathrm{a}$ \\
\hline Saco plástico & $13,81 \pm 0,03 \mathrm{a}$ & $0,43 \pm 0,01 \mathrm{a}$ & $70,8 \pm 0,05 \mathrm{c}$ & $4,8 \pm 0,20 \mathrm{a}$ & $10,80 \pm 0,04 \mathrm{a}$ & $2,89 \pm 0,04 \mathrm{~b}$ \\
\hline Saco de TNT & $14,05 \pm 0,05 \mathrm{a}$ & $0,44 \pm 0,01 \mathrm{a}$ & $77,6 \pm 0,04 \mathrm{~b}$ & $4,6 \pm 0,18 \mathrm{a}$ & $11,11 \pm 0,07 \mathrm{a}$ & $3,08 \pm 0,05 \mathrm{~b}$ \\
\hline
\end{tabular}

Médias seguidas pela mesma letra, nas colunas, não diferem pelo teste de Tukey $(\mathrm{p}<0,05)$.

TABELA3 3 - Cor da epiderme em frutos de macieiras 'Imperial Gala' submetidos ao ensacamento pré-colheita, em pomar conduzido sob sistema orgânico. São Joaquim-SC, safras 2007/2008 e 2008/2009.

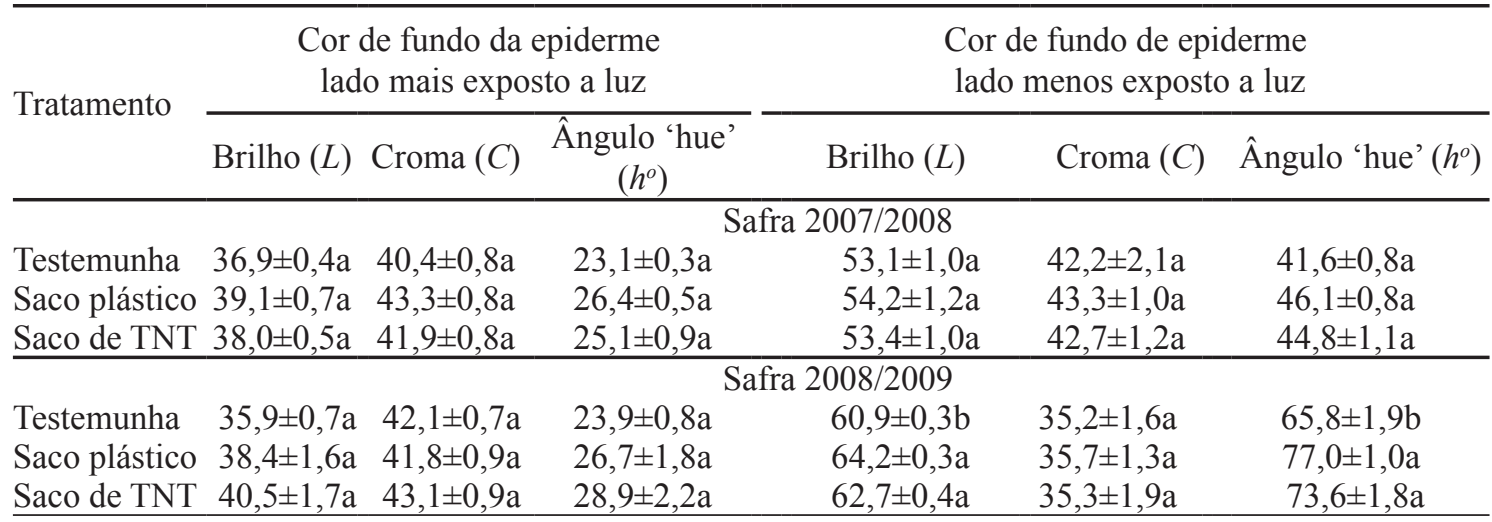

Médias seguidas pela mesma letra, nas colunas, não diferem pelo teste de Tukey $(\mathrm{p}<0,05)$. 
TABELA 4 - Densidade, cor vermelha, severidade de "russet" e incidência de queimadura de sol em frutos de macieira 'Imperial Gala' submetidos ao ensacamento pré-colheita, em pomar conduzido sob sistema orgânico. São Joaquim-SC, safras 2007/2008 e 2008/2009.

\begin{tabular}{|c|c|c|c|c|}
\hline Tratamento & Cor vermelha $(\%)$ & Densidade $\left(\mathrm{g} \mathrm{cm}^{-3}\right)$ & "Russet" $\left(\mathrm{cm}^{2}\right.$ fruto $\left.^{-1}\right)$ & Queimadura de sol (\%) \\
\hline & \multicolumn{4}{|c|}{ Safra $2007 / 2008$} \\
\hline Testemunha & $96,3 \pm 1,2 \mathrm{a}$ & $0,86 \pm 4,31 \mathrm{a}$ & $4,14 \pm 0,12 \mathrm{a}$ & $0,65 \pm 0,85 \mathrm{~b}$ \\
\hline Saco plástico & $97,3 \pm 0,8 \mathrm{a}$ & $0,79 \pm 3,21 \mathrm{a}$ & $4,11 \pm 0,16 \mathrm{a}$ & $1,14 \pm 6,64 \mathrm{a}$ \\
\hline \multirow[t]{2}{*}{ Saco de TNT } & $95,6 \pm 0,8 \mathrm{a}$ & $0,76 \pm 5,03 \mathrm{a}$ & $4,17 \pm 0,18 \mathrm{a}$ & $0,75 \pm 1,99 \mathrm{~b}$ \\
\hline & \multicolumn{4}{|c|}{ Safra $2008 / 2009$} \\
\hline Testemunha & $80,1 \pm 1,2 \mathrm{a}$ & $0,84 \pm 4,30 \mathrm{a}$ & $3,61 \pm 0,12 b$ & $0,94 \pm 3,75 b$ \\
\hline Saco plástico & $78,5 \pm 0,7 \mathrm{a}$ & $0,83 \pm 2,89 \mathrm{a}$ & $4,97 \pm 0,09 \mathrm{ab}$ & $4,24 \pm 0,01 \mathrm{a}$ \\
\hline Saco de TNT & $78,3 \pm 0,9 \mathrm{a}$ & $0,84 \pm 3,08 \mathrm{a}$ & $6,45 \pm 0,16 \mathrm{a}$ & $1,25 \pm 1,02 b$ \\
\hline
\end{tabular}

Médias seguidas pela mesma letra, nas colunas, não diferem pelo teste de Tukey $(\mathrm{p}<0,05)$.

\section{CONCLUSÕES}

O ensacamento de frutos com embalagens plásticas microperfuradas e de tecido não texturizado (TNT), em macieiras 'Imperial Gala' cultivadas sob sistema orgânico:

1-Protege os frutos de danos causados por mosca-das-frutas (A. fraterculus), mariposa-oriental (G. molesta) e lagarta-enroladeira (B. salubricola).

2-Não reduz a incidência da sarna-da-macieira (Venturia inaequalis) e podridão-amarga (Colletotrichum gloeosporioides) nos frutos.

3-Não interfere na percentagem de cor vermelha e no teor de cálcio, porém pode acelerar a maturação dos frutos.

\section{AGRADECIMENTOS}

Os autores agradecem ao agricultor Velocino Bolzani Neto, pela disponibilização do pomar para a realização deste trabalho, e ao apoio financeiro do MCT/CNPq/CT-HIDRO e FAPESC, através do projeto FUNJAB/FAPESC/Conv. 15915/2007-8.

\section{REFERÊNCIAS}

AMARANTE, C.; BANKS, H.N.; MAX, S. Preharvest bagging improves packout and fruit quality of pears (Pyrus communis). Journal of Crop and Horticultural Science, Wellington, v.30, n.2, p.9398, 2002a.
AMARANTE, C.; BANKS, H.N.; MAX, S. Effect of preharvest bagging on fruit quality and postharvest physiology of pears (Pyrus communis). Journal of Crop and Horticultural Science, Wellington, v.30, n.2, p.99-107, 2002b.

AMARANTE, C.V.T.; STEFFENS, C.A.; MAFRA, A.L.; ALBUQUERQUE, J.A. Yield and fruit quality of apple orchards under conventional and organic production systems. Pesquisa Agropecuária Brasileira, Brasília, v.43, n.3, p.333-340, 2008.

ASSOCIAÇÃO BRASILEIRA DE PRODUTORES DE MAÇÃ. Informações estatísticas. 2003. Disponível em: <http://www.abpm.org.br/ informações. htm>. Acesso em: 20 jun. 2009.

BIASI, A.L.; PERESSUTI, R.A.; TELLES, C.A.; ZANETTE, F.; MIO, L.L.M. de. Qualidade de frutos de caqui 'Jiro' ensacados com diferentes embalagens. Semina: Ciências Agrárias, Curitiba, v.28, n.2, p.213-118, 2007.

BONETI, J.I.S.; KATSURAYAMA, Y.; BLEICHER, J. Doenças da macieira. In: EPAGRI. A cultura da macieira. Florianópolis, 2002. p.527-555.

CAMILO, A.P.; DENARDI, F. Cultivares: descrição e comportamento no Sul do Brasil. In: EPAGRI. A cultura da macieira. Florianópolis, 2002. p.527555 .

COELHO, L.R.; LEONEL, S.; CROCOMO, B.W. Avaliação de diferentes materiais no ensacamento de pêssegos. Revista Brasileira de Fruticultura, Jaboticabal, v.30, n.3, p.822-826, 2008a. 
COELHO, L. R.; LEONEL. S.; CROCOMO, B. W.; LABINAS, M. A. Controle de pragas no pessegueiro através do ensacamento de frutos. Ciência e Agrotecnologia. Lavras, v. 32, n.6, p.1743-1747, 2008 b.

CHITARRA, F.M.I.; CHITARRA, B.A. Pós-colheita de frutas e hortaliças: fisiologia e manuseio. Lavras: UFLA, 2005. 430p.

FAORO, I.D. Técnica e custo para o ensacamento de frutos de pera-japonesa. Revista Brasileira de Fruticultura, Jaboticabal, v.25, n.2, p.339-340, 2003.

HOFMAN, J.P.; DARYL, C.; JOYCE, I.G.; MEBURG, G.F. Bagging of mango (Mangifera indica cv. 'Keitt') fruit influences fruit quality and mineral composition. Postharvest Biology and Technology, Amsterdam, v.12, n.32, p.83-91, 1997.

JIA, J.H.; ARAKI, A.; AKAMOTO, G. Influence of fruit bagging on aroma volatiles and skin coloration of 'Hakuho' peach (Prunus persica Batsch). Postharvest Biology and Technology, Amsterdam, v.35, n.2, p.61-68, 2004.

JORDÃO, A.L.; NAKANO, O. Ensacamento de frutos de tomateiro visando ao controle de pragas e à redução de defensivos. Scientia Agricola, Piracicaba, v.59, n.2, p.281-289, 2002.

KOOARIYALKUL, S.; SARDSUD, V. Bagging of lychee fruit to reduce postharvest disease In: COATES, L.M.; HOFMAN, P.J.; JOHNSON, G.I. (Ed.). Disease control and storage life extension in fruit. Canberra: ACIAR, 1998. p.92-110. (Proceedings, 81)

MARTINS, M.C.; AMORIN, L.; LOURENÇO, S.A.; GUTIERREZ, A.S.S.; WATANABE, H.S. Incidência de danos pós-colheita em goiabas no mercado atacadista de São Paulo e sua relação com a prática de ensacamento dos frutos. Revista Brasileira de Fruticultura, Jaboticabal, v.29, n.2, p.245-248, 2007.
MICHELETTI, S.M.F.B.; MELO, A.G.S.; BARBOSA, G.V.S.; GOMES, F.L. Controle de Cerconota anonella (SEPP.) (Lep.: Oecophoridae) e de Bephratelloides pomorum (FAB.) (Hym.: Eurytomidae) em frutos de graviola (Annona muricata L.). Revista Brasileira de Fruticultura, Jaboticabal, v.23, n.3, p.722-725, 2001.

OSTAPIV, F.; MAZARO, S.M.; DONAZZOLO, J.; CITADIN, A.; LINK, M.; GOUVÊA, A. Influência do ensacamento sobre a qualidade da uva 'Vênus'. Synergismus Scyentifica, Pato Branco, v.1, n.1, p.1-4, 2006.

PINHEIRO, S.C.S. Qualidade de goiabas ensacadas e manejadas com diferentes produtos fitossanitários, sob manejo orgânico. 2006. 106 F. Tese (Doutorado em Fitotecnia)- Universidade Federal de Viçosa, Viçosa, 2006.

SANTOS, P.J.; WAMSER, F.A. Efeito do ensacamento de frutos sobre danos causados por fatores bióticos e abióticos em pomar orgânico de macieira. Revista Brasileira de Fruticultura, Jaboticabal, v.28, n.2, p.168-171, 2006.

SANTOS, P.J.; WAMSER, F.A.; DENARDI, F. Qualidade de frutos ensacados em diferentes genótipos de macieira. Ciência Rural, Santa Maria, v.37, n.6, p.1614-1620, 2007.

SAS INSTITUTE. Getting started with the SAS learning edition. Cary: SAS, 2002. 200p.

SIGNES, A.J.; BURLÓ, F.; MARTÍNEZ-SÁNCHEZ, F.; CARBONELL-BARRACHINA, A.A. Effects of preharvest bagging on quality of black table grapes. World Journal of Agricultural Sciences, Rennes, v.3, n.1, p.32 - 38, 2007. 